\title{
The medical management of missed miscarriage: outcomes from a prospective, single-centre, Australian cohort
}

Scott G Petersen MBBS, FRANZCOG, CMFM, Maternal Fetal Medicine Specialist ${ }^{1}$

Anneliese R Perkins FRANZCOG, MBBS Obstetrics Registrar

Kristen S Gibbons BInfoTech, BMaths(Hons),

Julia I Bertolone BNurs,

Registered Nurse, Early Pregnancy Assessment Unit

\section{Kassam Mahomed MBBS, FRANZCOG Obstetrician Gynaecologist,} and Senior Obstetrician

1 Mater Mothers' Hospital, Brisbane, QLD.

2 Mater Medical Research Institute, Brisbane, QLD.

3 Ipswich Hospital, Brisbane, QLD.

Scott.Petersen@ mater.org.au

MJA 2013; 199: 341-346 doi: 10.5694/mjal2.11813

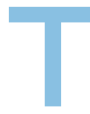
he medical management of miscarriage involves administering a medication to induce complete miscarriage. Misoprostol is the medication recommended for this purpose, despite this use being "offlabel".1,2 Most commonly indicated for missed miscarriage, ${ }^{3,4}$ medical management has been demonstrated to effectively expedite evacuation of the uterus compared with expectant management and safely reduce the need for surgical management. 5,6 High rates of satisfaction have been reported with medical management. ${ }^{3,7}$

Despite clinical trials showing that medical management is an acceptable alternative to surgical management, ${ }^{3-8}$ it has not been widely implemented into clinical practice in Australia. Until recently, the reported clinical experience in Australia was limited to one randomised trial involving 12 women with incomplete or inevitable miscarriages. ${ }^{9}$ This trial comparing all three methods of managing miscarriage was stopped because of poor support, with only $22 \%$ of eligible women recruited. A survey of general practitioners in Victoria reported that $48 \%$ were aware of pharmacological methods of managing miscarriage and only $8 \%$ had experience with medical management. ${ }^{10}$

We report the prospective clinical outcomes and patient experience after the medical management of missed miscarriage on an outpatient basis at a single Australian hospital.

\section{Methods}

We performed a descriptive study to evaluate a protocol for the medical management of missed miscarriage between 6 weeks and 12 weeks, 6 days of gestation, implemented at the Mater Mothers' Hospital, Brisbane.

\section{Abstract}

Objective: To report the prospective outcomes of medical management of missed miscarriage before 13 weeks' gestation from an Australian cohort.

Design: Descriptive study of a cohort selected out of a randomised controlled trial.

Setting: Outpatient management at a maternity hospital between 1 May 2007 and 28 July 2010.

Participants: 264 women requesting medical management of missed miscarriage.

Main outcome measures: Number of doses of misoprostol required, unscheduled visits for care, findings at ultrasound follow-up, requirement for surgical management, number of cases of gestational trophoblastic disease (GTD), and self-reported patient experience.

Results: 107 women (40.5\%) received a repeat dose of misoprostol, and 79 women (29.9\%) made unscheduled visits for care. Among the 241 women with Day 7 ultrasound follow-up, a gestational sac was found in 32 women (13.3\%), indicating failure of medical management. Complete miscarriage was induced without the need for surgery in 206 women (78.0\%). Surgery was performed as an emergency in 13 women (4.9\%). Twelve women (4.5\%) had surgery for ongoing bleeding after medical management, and four of these did not have chorionic villi on histopathological examination. Five women (1.9\%) had GTD, which was managed incidentally under the protocol. Among those who returned patient questionnaires, $73.0 \%$ of participants (116/159) indicated that they would recommend medical management of miscarriage to other women, while $18.2 \%$ (29/159) indicated that they would undergo surgery next time.

Conclusion: The medical management of missed miscarriage on an outpatient basis is safe and effective.

Trial registration: Australian New Zealand Clinical Trials Registry ACTRN12612000150842.

The study cohort consisted of women managed under this protocol from 1 May 2007 to 28 July 2010. The study was approved by the Mater Health Services Human Research Ethics Committee.

Participants were selected from a randomised controlled trial (RCT) (ACTRN12612000150842) conducted over two study sites, which compared $400 \mu \mathrm{g}$ and $800 \mu \mathrm{g}$ doses of misoprostol administered intravaginally in the outpatient management of miscarriage. ${ }^{11}$ This study enrolled 310 women, including 27 with incomplete and 283 with missed miscarriage. The trial showed equivalence between the two doses for the induction of complete miscarriage.
The protocol has been described previously in detail.11 Missed miscarriage was defined by the presence of an intrauterine gestational sac (GS) with or without a fetal pole at ultrasound assessment, irrespective of the indication for the scan. Gestational age was calculated with certain menstrual dates or, if unknown, ultrasound criteria.

Women requesting medical management were treated as outpatients at the gynaecology department. Misoprostol $(400 \mu \mathrm{g}$ or $800 \mu \mathrm{g})$ was administered intravaginally before discharge home into the care of a responsible adult. Written information about what to expect and a script for analgesia (paracetamol with codeine, and ibuprofen) were 
1 Characteristics and clinical outcomes of 264 women undergoing medical management of missed miscarriage*

\begin{tabular}{|c|c|c|c|c|c|c|c|c|c|c|c|}
\hline \multirow[b]{2}{*}{ Characteristics } & \multirow[b]{2}{*}{$\begin{array}{c}\text { Total } \\
\left(n=264^{\dagger}\right)\end{array}$} & \multicolumn{2}{|c|}{$\begin{array}{c}\text { No. of misoprostol } \\
\text { doses }\end{array}$} & \multicolumn{2}{|c|}{$\begin{array}{l}\text { Day } 7 \text { TVUSS } \\
\text { findings }\end{array}$} & \multicolumn{4}{|c|}{ Surgical management } & \multicolumn{2}{|c|}{ Unscheduled visits for care } \\
\hline & & $\begin{array}{c}\text { One dose } \\
(n=157)\end{array}$ & $\begin{array}{c}\text { Repeat } \\
\text { dose } \\
(n=107)\end{array}$ & $\begin{array}{c}\text { GS } \\
\text { present } \\
(n=32)\end{array}$ & $\begin{array}{c}\text { No GS } \\
(n=209)\end{array}$ & $\begin{array}{l}\text { Emergency } \\
\text { or requested } \\
(n=15)\end{array}$ & $\begin{array}{c}\text { Day 7 TVUSS } \\
\text { criteria for } \\
\text { failure }(n=31)\end{array}$ & $\begin{array}{c}\text { Clinically } \\
\text { suspected } \\
\text { RPOC }(n=12)\end{array}$ & $\begin{array}{c}\text { No } \\
\text { surgery } \\
(n=206)\end{array}$ & $\begin{array}{c}\text { Acute } \\
\text { presentation } \\
(n=55)\end{array}$ & $\begin{array}{c}\text { No acute } \\
\text { presentation } \\
(n=209)\end{array}$ \\
\hline \multicolumn{12}{|c|}{ Maternal characteristics } \\
\hline $\begin{array}{l}\text { Mean age in } \\
\text { years (SD) }\end{array}$ & $31.4(5.8)$ & $31.4(5.9)$ & $31.4(5.7)$ & $32.8(5.9)$ & $31.5(5.9)$ & $30.2(3.7)$ & $32.1(6.1)$ & $31.2(4.4)$ & $31.4(6.0)$ & $30.5(6.1)$ & $31.6(5.7)$ \\
\hline $\begin{array}{l}\text { Median gravida } \\
\text { (range) }\end{array}$ & $2(1-13)$ & $2(1-13)$ & $2(1-13)$ & $2(1-10)$ & $2(1-13)$ & $2(1-6)$ & $2(1-10)$ & $2(1-6)$ & $2(1-13)$ & $2(1-13)$ & $2(1-13)$ \\
\hline Nulliparity & $\begin{array}{c}118 \\
(44.7 \%)\end{array}$ & $\begin{array}{c}67 \\
(42.7 \%)\end{array}$ & $\begin{array}{c}51 \\
(47.7 \%)\end{array}$ & $\begin{array}{c}15 \\
(46.9 \%)\end{array}$ & $\begin{array}{c}96 \\
(45.9 \%)\end{array}$ & $\begin{array}{c}5 \\
(33.3 \%)\end{array}$ & $\begin{array}{c}15 \\
(48.4 \%)\end{array}$ & $\begin{array}{l}5 \\
(41.7 \%)\end{array}$ & $\begin{array}{c}93 \\
(45.1 \%)\end{array}$ & $\begin{array}{c}19 \\
(34.5 \%)\end{array}$ & $\begin{array}{c}99 \\
(47.4 \%)\end{array}$ \\
\hline $\begin{array}{l}\text { Prior caesarean } \\
\text { section } \ddagger\end{array}$ & $\begin{array}{c}51 / 262 \\
(19.5 \%)\end{array}$ & $\begin{array}{l}33 / 156 \\
(21.2 \%)\end{array}$ & $\begin{array}{l}16 / 106 \\
(15.1 \%)\end{array}$ & $\begin{array}{c}4 / 31 \\
(12.9 \%)\end{array}$ & $\begin{array}{l}41 / 208 \\
(19.7 \%)\end{array}$ & $\begin{array}{c}3 / 15 \\
(20.0 \%)\end{array}$ & $\begin{array}{c}4 / 31 \\
(12.9 \%)\end{array}$ & $\begin{array}{c}7 / 12 \\
(58.3 \%)\end{array}$ & $\begin{array}{l}37 / 204 \\
(18.1 \%)\end{array}$ & $\begin{array}{c}15 / 54 \\
(27.8 \%)\end{array}$ & $\begin{array}{l}34 / 208 \\
(16.3 \%)\end{array}$ \\
\hline \multicolumn{12}{|c|}{ Pregnancy characteristics of miscarriage } \\
\hline $\begin{array}{l}\text { Mean } \\
\text { gestational age } \\
\text { in weeks (SD) }\end{array}$ & $9.7(2.5)$ & $9.7(2.5)$ & $9.7(2.4)$ & $9.6(2.5)$ & $9.7(2.5)$ & $9.9(2.4)$ & $9.7(2.6)$ & $10.3(2.1)$ & $9.6(2.5)$ & 10.(2.5) & $9.5(2.4)$ \\
\hline $\begin{array}{l}\text { Fetal pole } \\
\text { present }{ }^{\ddagger}\end{array}$ & $\begin{array}{l}126 / 173 \\
(72.8 \%)\end{array}$ & $\begin{array}{c}\text { 79/104 } \\
(76.0 \%)\end{array}$ & $\begin{array}{c}47 / 69 \\
(68.1 \%)\end{array}$ & $\begin{array}{c}17 / 22 \\
(77.3 \%)\end{array}$ & $\begin{array}{l}96 / 134 \\
(71.6 \%)\end{array}$ & $\begin{array}{c}13 / 17 \\
(76.5 \%)\end{array}$ & $\begin{array}{c}16 / 21 \\
(76.2 \%)\end{array}$ & $\begin{array}{c}5 / 10 \\
(50.0 \%)\end{array}$ & $\begin{array}{c}92 / 125 \\
(73.6 \%)\end{array}$ & $\begin{array}{c}30 / 40 \\
(75.0 \%)\end{array}$ & $\begin{array}{c}96 / 133 \\
(72.2 \%)\end{array}$ \\
\hline \multicolumn{12}{|c|}{ Clinical management characteristics } \\
\hline $\begin{array}{l}\text { Median days } \\
\text { to treatment } \\
\text { (range) }\end{array}$ & $0(0-26)$ & $0(0-26)$ & $0(0-21)$ & $0(0-26)$ & $0(0-21)$ & $0(0-2)$ & $0(0-26)$ & $0(0-9)$ & $0(0-21)$ & $0(0-13)$ & $0(0-26)$ \\
\hline $\begin{array}{l}800 \mu g \\
\text { misoprostol } \\
\text { dose }\end{array}$ & $\begin{array}{c}128 \\
(48.5 \%)\end{array}$ & $\begin{array}{c}85 \\
(54.1 \%)\end{array}$ & $\begin{array}{c}43 \\
(40.2 \%)\end{array}$ & $\begin{array}{c}12 \\
(37.5 \%)\end{array}$ & $\begin{array}{c}106 \\
(50.7 \%)\end{array}$ & $\begin{array}{c}7 \\
(46.7 \%)\end{array}$ & $\begin{array}{c}11 \\
(35.5 \%)\end{array}$ & $\begin{array}{c}7 \\
(58.3 \%)\end{array}$ & $\begin{array}{c}103 \\
(50.0 \%)\end{array}$ & $\begin{array}{c}26 \\
(47.3 \%)\end{array}$ & $\begin{array}{c}102 \\
(48.8 \%)\end{array}$ \\
\hline $\begin{array}{l}\text { Second } \\
\text { misoprostol } \\
\text { dose }\end{array}$ & $\begin{array}{c}107 \\
(40.5 \%)\end{array}$ & - & - & $\begin{array}{c}17 \\
(53.1 \%)\end{array}$ & $\begin{array}{c}84 \\
(40.2 \%)\end{array}$ & $\begin{array}{c}5 \\
(33.3 \%)\end{array}$ & $\begin{array}{c}18 \\
(58.1 \%)\end{array}$ & $\begin{array}{c}3 \\
(25.0 \%)\end{array}$ & $\begin{array}{c}81 \\
(39.3 \%)\end{array}$ & $\begin{array}{c}11 \\
(20.0 \%)\end{array}$ & $\begin{array}{c}96 \\
(45.9 \%)\end{array}$ \\
\hline
\end{tabular}

GS = gestational sac. RPOC = retained products of conception. TVUSS = transvaginal ultrasound scan. *An exploratory secondary analysis was performed to assess for associations between patient characteristics and each of the four clinical outcomes. $P>0.05$ was recorded for all analyses, except number of doses and $800 \mu \mathrm{\mu g}$ dose $(P=0.033)$ and surgical management and prior caesarean section $(P=0.006)$. † Seven women with recurrent miscarriages were managed twice under the protocol. ¥ Incomplete dataset for prior caesarean section (data for 262 women) and fetal pole present (data for 173 women). No difference was identified for prior caesarean section on analysis of all women undergoing surgical management compared with no surgical management $(24.1 \%$ v $18.1 \% ; P=0.348)$.

provided. Rhesus-negative women were administered $625 \mathrm{IU}$ of rhesus D immunoglobulin intramuscularly. All women were encouraged to collect any tissue passed for histopathological examination.

Clinical follow-up was arranged for the next day (Day 1), Day 3, Day 7 and at 6 weeks. The dose of misoprostol given at presentation was repeated the next day if the products of conception had not been passed. A transvaginal ultrasound scan (TVUSS) was arranged for Day 7. On Day 3 and at 6 weeks, all women were given questionnaires about patient experience and satisfaction. Planned followup was to be completed at 6 weeks if results of a urine test for $\beta$-human chorionic gonadotropin ( $\beta \mathrm{hCG}$ ) were negative. Further follow-up was at the discretion of the attending gynaecologist.

Miscarriage completion was evaluated by gynaecologists on the basis of clinical assessment and the findings of the Day 7 TVUSS. Under the protocol, the miscarriage was considered complete without the need for surgery if there was a negative result of a urine $\beta$ hCG test and a spontaneous return to a normal menstrual cycle. Criteria defining failure of medical management at the Day 7 TVUSS were used to guide decision making about surgical management. ${ }^{3}$ The TVUSS criteria indicating surgery were a persistent intrauterine GS or an endometrial thickness greater than $30 \mathrm{~mm}$. Clinical indications for surgery before the Day 7 TVUSS included excessive bleeding or pain causing haemodynamic compromise, suspected sepsis or patient request. The decision to perform surgery for retained products of conception (RPOC) at any time during follow-up when there was persistent or abnormal vaginal bleeding was made pragmatically by consultant gynaecologists. Surgical evacuation of the uterus was performed by suction aspiration. Histopathological examination of all specimens was recommended to confirm the presence of chorionic villi, and to exclude gestational trophoblastic disease (GTD) and chronic endometritis. Results were reported as negative for RPOC if chorionic villi were not found after examination of the entire specimen.
The medical charts and any related imaging and pathology reports of all women were reviewed and returned patient questionnaires were analysed to document clinical outcomes and patient experience.

\section{Statistical analysis}

Statistical significance was determined for categorical variables with the Fisher exact test or $\chi^{2}$ test, and for continuous variables with standard parameteric or non-parametric tests (as determined by the number of groups analysed). $P$ less than 0.05 was considered clinically significant. Statistical analysis was performed with GraphPad Prism version 5.0.

\section{Results}

A total of 264 women with missed miscarriage were treated. At presentation, $136(51.5 \%)$ received the $400 \mu \mathrm{g}$ and $128(48.5 \%)$ received the $800 \mu \mathrm{g}$ dose of misoprostol. The characteristics of the study population are given in Box 1. The Day 7 TVUSS was performed in 241 women (91.3\%); 23 women 
2 Clinical outcomes matched to the Day 7 transvaginal ultrasound scan (TVUSS) findings of 264 women undergoing medical management of missed miscarriage

\begin{tabular}{|c|c|c|c|c|c|c|c|}
\hline TVUSS findings & $\begin{array}{c}\text { Total } \\
(n=264)\end{array}$ & $\begin{array}{c}\text { Repeat } \\
\text { dose } \\
(n=107)\end{array}$ & $\begin{array}{l}\text { Unscheduled } \\
\text { visits for care } \\
\quad(n=73)\end{array}$ & $\begin{array}{c}\text { Surgical } \\
\text { management } \\
(n=58)\end{array}$ & $\begin{array}{l}\text { Median days to } \\
\text { surgery (range) } \\
\quad(n=58)\end{array}$ & $\begin{array}{l}\text { No chorionic villi on } \\
\text { histopathological } \\
\text { examination }(n=5)\end{array}$ & $\begin{array}{c}\text { Gestational } \\
\text { trophoblastic } \\
\text { disease }(n=5)\end{array}$ \\
\hline \multicolumn{8}{|c|}{ Successful medical management } \\
\hline $\begin{array}{l}\text { No GS present; } \\
\mathrm{ET} \leqslant 30 \mathrm{~mm}\end{array}$ & $205(77.7 \%)$ & $80(74.8 \%)$ & $54(74.0 \%)$ & $12 *(20.7 \%)$ & $46(20-98)$ & $4 *(80.0 \%)$ & $3(60.0 \%)$ \\
\hline \multicolumn{8}{|c|}{ Failure of medical management } \\
\hline $\begin{array}{l}\text { No GS present; } \\
\text { ET > } 30 \mathrm{~mm}\end{array}$ & $4(1.5 \%)$ & $4(3.7 \%)$ & $2(2.7 \%)$ & $3(5.2 \%)$ & $22(9-41)$ & 0 & 0 \\
\hline GS present & $32(12.1 \%)$ & $17(15.9 \%)$ & $4(5.5 \%)$ & $28(48.3 \%)$ & $10(7-37)$ & 0 & $2(40.0 \%)$ \\
\hline $\begin{array}{l}\text { Unknown (no } \\
\text { TVUSS) }\end{array}$ & $23(8.7 \%)$ & $6(5.6 \%)$ & $13(17.8 \%)$ & $15^{\dagger}(25.9 \%)$ & $4(0-10)$ & $1(20.0 \%)$ & 0 \\
\hline
\end{tabular}

GS = gestational sac. ET = endometrial thickness. *Among the 12 women managed surgically after successful medical management, there was no significant difference in ET between the four women with no chorionic villi (median, $12.15 \mathrm{~mm}$; range, 2.0-26.4 mm) and the eight women with confirmed chorionic villi (median, $18.75 \mathrm{~mm}$; range, $5.8-27.0 \mathrm{~mm} ; P=0.368$ ) on histopathological examination. There was also no significant difference in days to surgery between those with no chorionic villi (median, 57; range, 44-98) and those with confirmed chorionic villi (median, 42; range, 20-77; $P=0.174$ ). $†$ Of the 15 women managed surgically who had unknown TVUSS characteristics, 13 had emergency surgery (surgery was arranged for three women at scheduled follow-up and for 10 at unscheduled visits), and two requested surgery.

did not have the TVUSS (15 underwent surgery; eight did not attend). Clinical follow-up to complete miscarriage or surgery was completed in all 264 women. Box 1 summarises the number of doses and unscheduled visits for care, Day 7 TVUSS outcomes and surgical management. Outcomes matched to the Day 7 TVUSS findings are described in Box 2.

\section{Day 7 TVUSS findings}

A GS was found in 32 women on median Day 7 (range, Day 6-12). No GS was identified in 209 women on median Day 7 (range, Day 1-21), and four of these had endometrial thickness $>30 \mathrm{~mm}$ (range, $34-45 \mathrm{~mm}$ on Days 6-7). Overall, 36 of the women who had TVUSS (14.9\%) met the criteria for failure of medical management.

\section{Surgical management}

Surgery was performed in 58 women (22.0\%). Emergency surgery was performed in 13 women for clinical indications. Two women requested surgery before Day 7. Of the 36 women with TVUSS criteria for failure, 31 (86.1\%) underwent surgery. Initially, nine continued conservative management and five of these (four with GS and one with endometrial thickness $>30 \mathrm{~mm}$ ) completed the miscarriage without surgery by 6 weeks - four continued expectantly, and one requested a repeat course of misoprostol. Of the 205 women with no TVUSS criteria for failure, 12 (5.9\%) underwent surgery for clinically suspected RPOC on median Day 46 (range, Day 20-98).

\section{Number of doses}

One hundred and seven women (40.5\%) received a repeat dose of misoprostol. If a repeat dose was required, the rate of failure using TVUSS criteria was significantly higher (15/140 [10.7\%] with one dose v 21/101 [20.8\%] with a repeat dose; $P=0.04$ ). There was no difference in the rate of surgery (32/157 [20.4\%] with one dose v 26/107 [24.3\%] with a repeat dose; $P=0.45$ ). Of the 13 women undergoing emergency surgery, three had a repeat dose.

\section{Unscheduled visits for care}

Seventy-nine women (29.9\%) made 86 unscheduled visits for care, with five women making two presentations and one woman presenting three times. Of these visits, 55 were acute presentations to hospital emergency departments and 31 were nonurgent reviews.

The acute presentations occurred on median Day 1 (interquartile range [IQR], Day 0-4; maximum, Day 23) and were related to miscarriage symptoms (pain and bleeding). These presentations led to admission for 21 women, with 10 undergoing emergency surgery and two requiring blood transfusions (one of 1 unit and one of 2 units). Four women were observed overnight in emergency departments.

The non-urgent reviews occurred on median Day 26 (IQR, Day 19-57; maximum, Day 97) and were related to abnormal bleeding, including two women who required postsurgical management. Of these 31 presentations, 15 were managed conservatively and 16 surgically, including four women with TVUSS criteria for failure who initially continued conservatively. Nine women were treated with antibiotics for suspected infection.

\section{Patient experience and satisfaction}

A total of 199 women (75.4\%) returned questionnaires (Box 3), but not all questions were answered (hence denominators vary). Fifty-three per cent of respondents (80/151) reported passing products of conception within 24 hours of receiving misoprostol. Seventy-nine women reported on the number of days of bleeding, with the median being 10 days (IQR, 6-14 days; maximum, 56 days). Among those who reported the approximate duration of bleeding, 23.2\% (35/151) reported bleeding for longer than 2 weeks. With regard to bleeding amount and pain severity, 32.8\% (60/183) reported heavier bleeding than expected and $42.8 \%$ (77/180) reported experiencing more severe pain than expected.

When asked if they would recommend medical management of miscarriage to other women, $73.0 \%$ (116/159) indicated that they would, while $18.2 \%$ (29/159) indicated that they would undergo surgery next time. Patient satisfaction is reported with Likert scales in Box 4.

\section{Histopathological examination}

One hundred and nine specimens from 104 pregnancies (39.4\%) were examined. Of the 206 women who did not have surgery, 47 (22.8\%) provided samples; chorionic villi were confirmed in all of these samples. After surgery, chorionic villi were not identified in specimens from five women: one specimen was collected at 
3 Patient experiences of medical management of missed miscarriage*

Questions and responses

No. of women (\%)

\begin{tabular}{|c|c|}
\hline \multicolumn{2}{|c|}{$\begin{array}{l}\text { Miscarriage - time to onset of symptoms (fresh bleeding or pain) } \\
(n=190)\end{array}$} \\
\hline Several hours & $127(66.8 \%)$ \\
\hline$<24$ hours & $47(24.7 \%)$ \\
\hline$<48$ hours & $12(6.3 \%)$ \\
\hline Nil & $4(2.1 \%)$ \\
\hline \multicolumn{2}{|c|}{ Miscarriage - time to pass products of conception $(n=151)$} \\
\hline$<24$ hours & $80(53.0 \%)$ \\
\hline$<48$ hours & $28(18.5 \%)$ \\
\hline After 3 days & $21(13.9 \%)$ \\
\hline Not after 1 week & $22(14.6 \%)$ \\
\hline \multicolumn{2}{|c|}{ Bleeding - enough to worry $(n=192)$} \\
\hline Yes & $70(36.5 \%)$ \\
\hline No & $122(63.5 \%)$ \\
\hline \multicolumn{2}{|c|}{ Bleeding - amount compared with expectations $(n=183)$} \\
\hline Much more than expected & $10(5.5 \%)$ \\
\hline More than expected & $50(27.3 \%)$ \\
\hline Same & $69(37.7 \%)$ \\
\hline Less than expected & $54(29.5 \%)$ \\
\hline \multicolumn{2}{|l|}{ Bleeding - duration $(n=151)$} \\
\hline Longer than 2 weeks & $35(23.2 \%)$ \\
\hline Longer than a period & $68(45.0 \%)$ \\
\hline Same & $28(18.5 \%)$ \\
\hline Less than a period & $20(13.2 \%)$ \\
\hline \multicolumn{2}{|l|}{ Pain - enough to worry $(n=193)$} \\
\hline Yes & $89(46.1 \%)$ \\
\hline No & $104(53.9 \%)$ \\
\hline \multicolumn{2}{|c|}{ Pain - severity compared with expectations $(n=180)$} \\
\hline Much more than expected & $23(12.8 \%)$ \\
\hline More than expected & $54(30.0 \%)$ \\
\hline Same & $56(31.1 \%)$ \\
\hline Less than expected & $47(26.1 \%)$ \\
\hline
\end{tabular}

Satisfaction - felt it was a good decision to undergo medical management $(n=156)$

Yes

$131(84.0 \%)$

No

$25(16.0 \%)$

Satisfaction - received appropriate information about miscarriage symptoms $(n=158)$
Yes
$142(89.9 \%)$
No
$16(10.1 \%)$

Satisfaction - received appropriate information about management at home $(n=158)$

Yes

No

$21(13.3 \%)$

Satisfaction - would have preferred hospital admission $(n=156)$ Yes $\quad 50(32.1 \%)$ No $106(67.9 \%)$

Emotional stress - increased by outpatient management $(n=153)$

Yes $40(26.1 \%)$

No $113(73.9 \%)$

Emotional stress - increased by awaiting effect of medical management $(n=159)$

Yes

$41(25.8 \%)$

No

$118(74.2 \%)$

* 199 women returned questionnaires; totals vary because not all

questions were answered by all respondents. emergency surgery for heavy bleeding on Day 3, and the other four were collected at surgery for suspected RPOC between Days 44 and 98. Each of these four women had a negative $\beta$ hCG test result before surgery. Chronic endometritis was reported in two of these women.

Five cases of GTD were identified on histopathological examination, including one complete and four partial molar pregnancies. Three cases were identified at surgery: two cases in women having surgery for failed medical management indicated by presence of a GS; and one in a woman having surgery for suspected RPOC on Day 62 with a positive $\beta$ hCG urine test result. Two cases were identified on examination of spontaneously passed tissue, and were managed conservatively without surgery. Chemotherapy was not required in any of the women. Serum $\beta$ hCG test results were negative ( $\beta$ hCG level <1.2 IU) by Day 50-55 in the two managed without surgery, and by Day 75-101 in those who had surgery.

\section{Discussion}

Our initial experience with the medical management of missed miscarriage is consistent with the published literature. ${ }^{3-8,12}$ Our results support offering medical management to women on an outpatient basis, and confirm that this form of management can be safely implemented into clinical practice.

Similar to other clinical studies, ${ }^{3,12}$ we report that the rate of failure using TVUSS criteria is higher if a repeat dose is required. Increased rates of failure with medical management have also been reported with delaying management after diagnosis and nulliparity. ${ }^{13,14}$ This suggests that factors unique to the index pregnancy, including myometrial receptivity, and not the treatment itself, may account for failure. Our study was not powered for a post-hoc secondary analysis of failed medical management. Miscarriage symptoms within 24 hours of treatment may increase success. ${ }^{14}$ Others have reported that prior caesarean delivery did not affect outcome. ${ }^{15}$

Our RCT involving this cohort showed that the dose of misoprostol used appears not to affect the rate of complete miscarriage; however, using a higher dose does increase the rate of fever or rigors experienced despite a reduced need for repeat administration. ${ }^{11}$

We provided written information and arranged frequent follow-up for our patients. Despite this, over onequarter made unscheduled visits for care. Miscarriage symptoms are a common reason for presentation to emergency departments, and are also frequent after surgical management. Previous studies have reported unscheduled visits in $18 \%-23 \%$ of patients after medical management and $8 \%-17 \%$ after surgery. 3,4

Most unscheduled presentations following medical management can be managed conservatively. ${ }^{1}$ Less than $10 \%$ of our cohort required acute admission to hospital and the rate of emergency surgery within 1 week was $4.9 \%$. This suggests that most women present seeking reassurance that the miscarriage symptoms they are experiencing are appropriate. Management on an outpatient basis may have contributed to this, with one-third indicating that they would have preferred hospital admission and one-quarter reporting that their emotional stress was increased by outpatient management.

While experiencing pain and bleeding during miscarriage may negatively affect the acceptability of medical management, 16 the method of miscarriage management has not been reported to affect psychological morbidity. ${ }^{17}$ The duration of bleeding is accepted to be longer after medical management than after surgery; however, the duration of pain and convalescence, transfusion requirement, and risk of infection and future fertility complications are not increased. 3,4,6,18 Surgery requires anaesthesia and carries unique risks, such as cervical injury and uterine perforation. It has been reported that women would prefer medical over surgical management if the effectiveness of medical management to induce complete miscarriage exceeded $65 \% .{ }^{19}$

The use of a single dose of misoprostol, repeated as clinically indicated, safely reduces but does not obviate the need for surgery. 3,8 Surgery remains the principal management for miscarriages complicated 


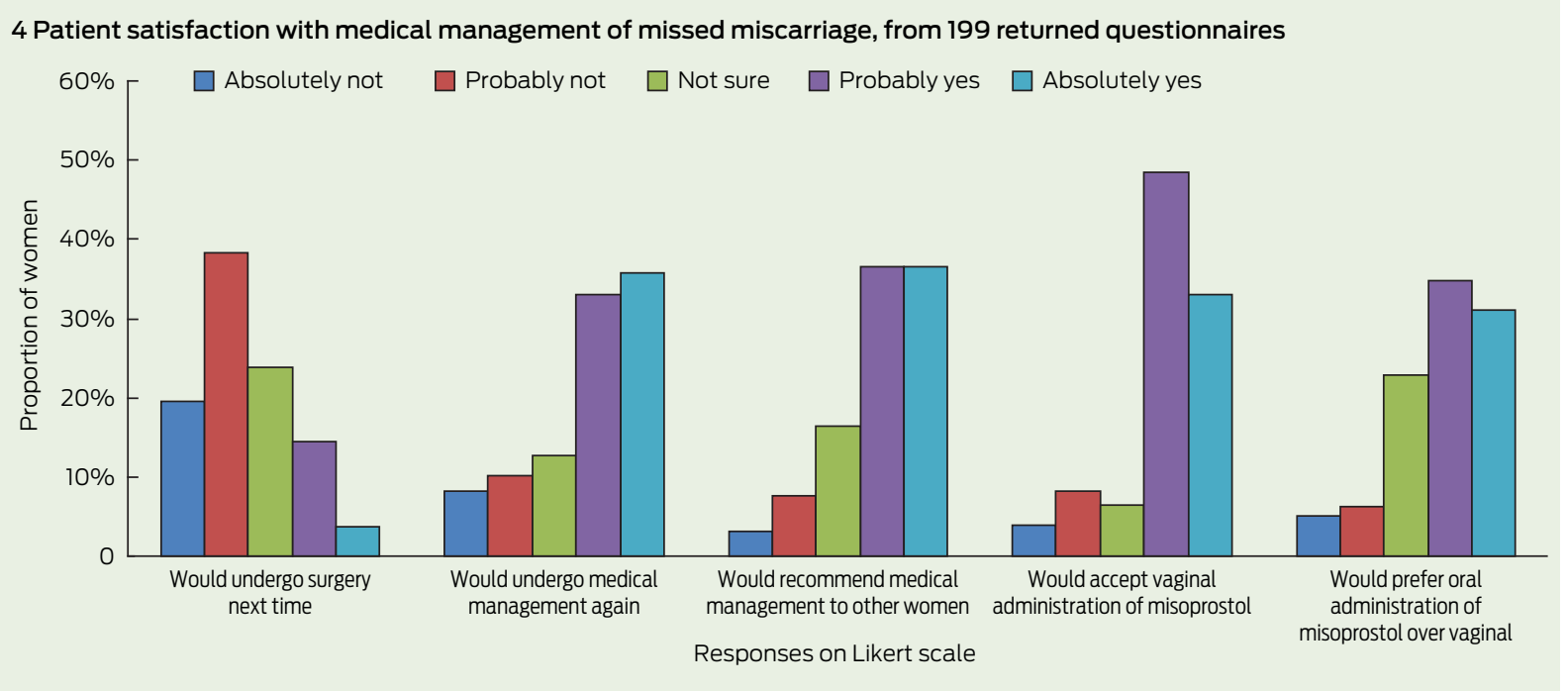

by haemodynamic compromise from excessive bleeding, sepsis or (suspected) GTD. ${ }^{1}$ Complications indicating surgical management are considered to affect less than $10 \%$ of miscarriages. ${ }^{16}$ Surgery should remain available electively to women who prefer that option.

Ultrasound evaluation of treatment success after medical management is standard practice, $3,4,7,8$ although a correlation between endometrial thickness and the need for surgical management is disputed. ${ }^{20} \mathrm{We}$ adopted published ultrasound criteria to guide our clinicians on the need for surgical management. ${ }^{3}$ Just over half of the surgical patients in our study met TVUSS criteria for failure.

Previous studies have restricted the evaluation of surgical management during follow-up to specified time frames after treatment with misoprostol, $, 3,7$ or to confirmation of chorionic villi at histopathological examination. ${ }^{7}$ We included all surgical patients and evaluated histopathological results in an attempt to differentiate women with RPOC from those with abnormal uterine bleeding. 20 Of the 12 women who underwent surgery for suspected RPOC, chorionic villi were not confirmed in four. Given that two had features of chronic endometritis and none had a significant $\beta$ hCG level before surgery, the ongoing bleeding in these four women suggests failure to return to an ovulatory cycle, rather than failure of medical management.

The routine pathological examination of tissue evacuated from the uterus to exclude an ectopic pregnancy or GTD has been challenged. ${ }^{21}$ While ultrasound is a powerful tool in the assessment of pregnancy location, differentiating a molar pregnancy from a failed early pregnancy remains difficult. ${ }^{22,23}$ In our cohort, five molar pregnancies were identified coincidentally out of $104(4.8 \%)$ on histopathological examination. Although the rate in our total cohort was undetermined, the incidence of hydatidiform molar pregnancies reported in a study of 1606 uncomplicated miscarriages managed surgically was $2.5 \% .{ }^{24}$ Even after apparently successful medical management, clinicians must remain vigilant to not miss signs of GTD. ${ }^{25}$

The medical management of missed miscarriage on an outpatient basis is clinically effective, safe and acceptable. Medical management reduces the need for surgery and can be routinely offered in cases of uncomplicated missed miscarriage. Consideration should be given to routinely performing a urine pregnancy test during follow-up after 6 weeks. Failure to return to normal menstruation with ongoing abnormal bleeding and persistence of a positive result of a serum $\beta$ hCG test warrants gynaecological review and consideration for surgical management to exclude GTD.

Acknowledgements: We are grateful to all the registrars, consultants and nursing staff who assisted with recruitment into the study and management of the participating women at the Mater Mothers' Hospital. We acknowledge the Mater Research Support Centre for their support and encouragement.

Competing interests: No relevant disclosures.

Received 12 Dec 2012, accepted 30 May 2013.

1 17th Expert Committee on the Selection of

Use of Essential Medicines. Proposal for the inclusion of misoprostol in the WHO model list of essential medicines. Geneva, March 2009. http://www.who.int/selection_medicines/ committees/expert/17/application/Miso_ Incl_2.pdf (accessed Jul 2010).

2 Royal Australian and New Zealand College of Obstetricians and Gynaecologists. The use of misoprostol in obstetrics. College statement C-Obs 12. November 2001. http:// www.ranzcog.edu.au/partially-comparable/ assessment-workshops-forms/logbook-a-tar/ doc_download/946-c-obs-12-the-use-ofmisoprostol-in-obstetrics.html (accessed Apr 2007).

3 Zhang J, Gilles JM, Barnhart K, et al. A comparison of medical management with misoprostol and surgical management for early pregnancy failure. N Engl J Med 2005; 353: 761-769.

4 Trinder J, Brocklehurst P, Porter R, et al. Management of miscarriage: expectant, medical, or surgical? Results of randomised controlled trial (miscarriage treatment (MIST) trial). BMJ 2006; 332: 1235-1240.

5 Sotiriadis A, Makrydimas G, Papatheodorou S, loannidis J. Expectant, medical, or surgical management of first trimester miscarriage: a meta-analysis. Obstet Gynecol 2005; 105 : 1104-1113.

6 Neilson JP, Hickey M, Vazquez J. Medical treatment for early fetal death (less than 24 weeks). Cochrane Database Syst Rev 2006; (3): CD002253.

7 Wood SL, Brain PH. Medical management of missed abortion: a randomized clinical trial. Obstet Gynecol 2002; 99: 563-566.

8 Heard MJ, Stewart GM, Buster JE, et al. Outpatient management of missed abortion with vaginal misoprostol. Obstet Gynecol 2002; 99 Suppl 4: 20S-21S.

9 Shelley JM, Healy D, Grover S. A randomised trial of surgical, medical and expectant management of first trimester spontaneous miscarriage. Aust N Z J Obstet Gynaecol 2005; 45: 122-127.

10 McLaren B, Shelley JM. Reported management of early-pregnancy bleeding and miscarriage by general practitioners in Victoria. Med J Aust 2002; 176: 63-66.

11 Petersen SG, Perkins A, Gibbons K, et al. Can we use a lower intravaginal dose of misoprostol in the medical management of miscarriage? A randomised controlled study. Aust N Z J Obstet Gynaecol 2013; 53: 64-73. 
12 Barceló F, De Paco C, López-Espín JJ, et al. The management of missed miscarriage in an outpatient setting: 800 versus $600 \mu g$ of vaginal misoprostol. Aust NZ J Obstet Gynaecol 2012; 52: 39-43.

13 Torre A, Huchon C, Bussieres L, et al. Immediate versus delayed medical treatment for firsttrimester miscarriage: a randomized trial. Am J Obstet Gynecol 2012; 206: 215.el-215.e6.

14 Creinin MD, Huang X, Westhoff C, et al. Factors related to successful misoprostol treatment for early pregnancy failure. Obstet Gynecol 2006; 107: 901-907.

15 Chen BA, Reeves MF, Creinin MD, et al. Misoprostol for treatment of early pregnancy failure in women with previous uterine surgery. Am J Obstet Gynecol 2008; 198: 626.el-626.e5.

16 Johnson N, Priestnall M, Marsay T, et al. A randomised trial evaluating pain and bleeding after a first trimester miscarriage treated surgically or medically. Eur $J$ Obstet Gynecol Reprod Biol 1997; 72: 213-215.

17 Nielsen S, Hahlin M, Möller A, Granberg S. Bereavement, grieving and psychological morbidity after first trimester spontaneous abortion: comparing expectant management with surgical evacuation. Hum Reprod 1996; 11: 1767-1770.

18 Blohm F, Hahlin M, Nielsen S, Milsom I. Fertility after a randomised trial of spontaneous abortion managed by surgical evacuation or expectant treatment. Lancet 1997; 349: 995.

19 GraziosiGC, Bruinse HW, Reuwer PJ, Mol BW. Women's preferences for misoprostol in case of early pregnancy failure. Eur $J$ Obstet Gynecol Reprod Biol 2006; 124: 184-186.

20 Reeves MF, Lohr PA, Harwood BJ, Creinin MD. Ultrasonographic endometrial thickness after medical and surgical management of early pregnancy failure. Obstet Gynecol 2008; 111: $106-112$.
21 Heath V, Chadwick V, Cooke I, et al. Should tissue from pregnancy termination and uterine evacuation routinely be examined histologically? BJOG 2000; 107: 727-730.

22 Sebire NJ, Rees H, Paradinas F, et al. The diagnostic implications of routine ultrasound examination in histologically confirmed early molar pregnancies. Ultrasound Obstet Gynecol 2001; 18: 662-665.

23 Kirk E, Papageorghiou AT, Condous G, et al. The accuracy of first trimester ultrasound in the diagnosis of hydatidiform mole. Ultrasound Obstet Gynecol 2007; 29: 70-75.

24 Tasci Y, Dilbaz S, Secilmis O, et al. Routine histopathologic analysis of product of conception following first-trimester spontaneous miscarriages. J Obstet Gynaecol Res 2005; 31: 579-582.

25 Sebire NJ. Hydatidiform mole and medical management of miscarriage. BMJ 2006; 332: 1454.

\section{source of medical information}

Australia's most trusted

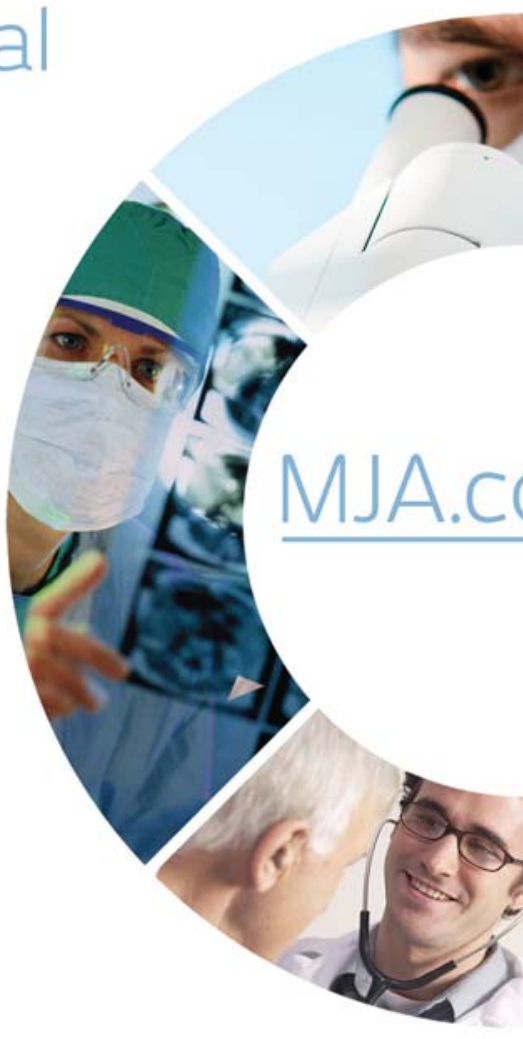

Leading the field in publishing medical research, commentary and clinical material. The MJA is continually expanding its presence in print and online to meet the needs of a modern world.

Read and interact with Australia's leading medical minds, access our archives, and keep up to date with your profession and the wider issues that influence health and health care. Join the MJA community

www.mja.com.au/subscribe subscriptions@mja.com.au 